\title{
СУЩНОСТНО-СОДЕРЖАТЕЛЬНЫЕ, СТРУКТУРНЫЕ И ФУНКЦИОНАЛЬНЫЕ ОСНОВЫ И ПАРАМЕТРЫ ПРОЯВЛЕНИЯ И ФОРМИРОВАНИЯ ИНФОРМАЦИОННОЙ КУЛЬТУРЫ ЛИЧНОСТИ
}

В статье рассматриваются современное понимание информационной культурь личности в аспектах её проявления и формирования. Раскрыты ведуице функции информационной культурь как сочиального и психолого-педагогического феномена. На основе анализа современных научных подходов предложено содержательное наполнение информачионной культуры личности. Оно представлено как субъектное проявление информационного мировоззрения, информационного поведения, информационного мышиления и информационной деятельности личности в комплексе специфических способностей, знаний, умений, навыков. Показано, что информационная культура личности имеет многояруснуло структуру, представленнуло когнитивным, иенностно-смысловым и содержательным (деятельностно-практическим) компонентами, раскрывающими её мировоззренческий, психологический, морально-этический, сочиальный и технологический параметры. Предложены направления работы по формированию информачионной культуры у учацихся.

Ключевые слова: информачия, информачиониая культура, компоненты информационной культуры, информационное мировоззрение, информационное поведение, информационное мыиление, информачионная деятельность, инфориачионная грамотность, информационные ресурсы, информациониье технологии, функции информационной культуры, формирование информационной культуры. ценности, мотивация, знания, умения, навыки, условия формирования информационной культуры.

\section{Sergey Bobryshov, Natalia Gorbatovsckaya \\ ESSENTIAL-SUBSTANTIAL, STRUCTURAL AND FUNCTIONAL BASES AND THE DEVELOPMENT PARAMETERS AND FORMATION OF INFORMATION CULTURE OF A PERSON}

The article deals with the modern understanding of the information culture of the person in the aspects of its manifestation and formation. The leading functions of information culture as a social, psychological and pedagogical phenomenon are revealed. On the basis of the analysis of modern scientific approaches the content content of information culture of the person is offered. It is presented as a subjective manifestation of information worldview, information behavior, information thinking and information activity of the individual in the complex of specific abilities, knowledge, skills. It is shown, that the information culture of the individual has a multi-tiered structure, represented by cognitive, value-semantic and meaningful (activity-practical) components, revealing its ideological, psychological, moral, ethical, social and technological parameters. The directions of work on the formation of information culture among students are proposed..

Key words: information, information culture, components of information culture, information Outlook, information behavior, information thinking, information activity, information literacy, information resources, information technologies, functions of information culture, formation of information culture, values, motivation, knowledge, skills, conditions of formation of information culture.

Bвedeнue / Introduction. Вся социальная, и в частности педагогическая, практика свидетельствуют, что мы вошли в новую стадию развития не просто коммуникационной, а цивилизационной организации общества (причем на уровне всех возрастов, в каждой нише материальной и 
духовной сфер жизни и деятельности: дома, в школе, на улице, практически во всех профессиях), которая характеризуется валовым возрастанием объема информации, источников её происхождения, многообразия функционирования, каналов распространения, способов видоизменения, а соответственно, глобального её значения для каждой личности и общества в целом. Информация становится не просто значимой частью культуры, предлагаемой подрастающему поколению для освоения в качестве определенного жизненного багажа и блага, а способом её существования. На ребенка сызмальства из самых разных источников обрушивается море нужной и ненужной, полезной, бесполезной и вредной, правдивой, достоверной и ложной информации, по определению несущей ему «культуру». Она буквально пропитывает его. И ребенок, подросток, часто сам того не ведая, не прикладывая к этому особых усилий и не контролируя, становится просто своеобразным сосудом, наполненным порой весьма гремучей смесью информации, при этом не всегда знающим и понимающим, к чему она ему, что разумного с этой информацией делать. Всё чаще речь идет о наступлении тотального информационного бескультурья. И если не так давно говорилось о необходимости «гармонизировать миры культуры и информации» [16], то сегодня уже следует вести речь о гармонизации человека и информации. А потому перед педагогами стоит непростая задача научить детей не только грамотно овладевать (эта задача стояла всегда), но и искусно владеть информацией, ответственно и с пользой её применять во всех сферах жизнедеятельности. Именно это сегодня является интегральным показателем достижения уровня просвещенности и цивилизованности, как «условие устойчивого и безопасного развития в принципиально новом культурно-образовательном пространстве» [2, с. 16].

Кроме того, информация (её многообразие, доступность, неконтролируемость обращения) стала важнейшей детерминантой и составляющей современной парадигмы образования, постулирующей идеи его непрерывности на протяжении всей жизни (в основе этой идеи формирование у учащихся убеждения в том, что всякое уже полученное ими знание весьма относительно, основу же его надежности создает лишь постоянное обновление и приращение знаний, а соответственно, работа по овладению всё новым и новым знанием), расширения роли самообразования (формирование убеждения, что школьное и в дальнейшем вузовское обучение ориентированы в своей основе на получение прежде всего строго регламентированного, адсорбированного и дозированного знания как общей минимальной базы, вряд ли дающей возможность осуществить подлинное саморазвитие, дальнейшую личностную и профессиональную самореализацию), усиления персональной ответственности за то, что ты знаешь, чем владеешь, где, как и с какой целью это применяешь. Это определяет необходимость формирования у обучающихся качественно нового образа и формата информационной культуры, выходящей за рамки технико-технологической включенности в процесс информатизации действительности (общества, образования, производства и т. д.).

Её формирование выступает одной из центральных задач каждого уровня образования. Но, чтобы успевать «за временем», нельзя упускать из вида вопрос о развитии феномена информационной культуры, нашего её понимания в функциональном значении, компонентном и содержательном наполнении. Ибо то, что вчера было уже вроде достаточно прояснено и описано философами, социологами, культурологами, психологами и педагогами (С. Г. Антонова, Ю. С. Брановский, В. А. Виноградов, Г. Г. Воробьев, Б. С. Гершунский, А. А. Греков, А. П. Ершов, Н. Б. Зиновьева, Ю. С. Зубов, В. А. Каймин, С. Д. Каракозов, Н. В. Лопатина, Н. И. Монахов, Т. А. Полякова, Н. М. Розенберг, Э. П. Семенюк, Н. А. Сляднева, Л. В. Скворцова, Г. А. Стародубова, А. Д. Урсул, И. Г. Хангельдиева и др.) сегодня приобретает новые содержание и дополнительные контексты звучания.

Maтериалы и методы / Materials and methods. В основу анализа проблемы положены научные материалы, раскрываюшие основы современного понимания информационной культуры личности как социального и психолого-педагогического феномена. В работе с материалами с позиций педагогической и социальной антропологии использованы методы системного, структурного и функционального анализа и синтеза; теоретического конструирования и прогнозирования. 
Результаты и обсуждение / Results and discussion. Разработка подходов, форм, методов, приемов работы по формированию информационной культуры у обучающихся в своей основе предполагает четкую ориентацию педагогов в следующих вопросах: в каких контекстах информационная культура связана с общей культурой человека (т. е. как она взаимосвязана с другими культурами личности); каков спектр функционала и ответственностей информационной культуры относительно обеспечения развития личности (это должно помочь достигнуть осознанного и ответственного отношения обучающихся к формированию у них информационной культуры, к самостоятельному её развитию); каково содержание информационной культуры личности как совокупности знаний, умений, навыков и способностей (т. е. что конкретно надо формировать и развивать у учащихся), а также каков компонентный состав информационной культуры (это позволяет систематизировать работу по формированию и диагностике укрупненных функционально-содержательных блоков информационной культуры).

Анализ работ по проблеме показал, что информационная культура личности исследователями определяется: а) как одно из проявлений общей культуры человека, обнаруживающейся в совокупности знаний и представлений, накопленных человечеством, которыми овладевает суббъект на этапах формирования собственной информационной культуры, а также во всех возможных видах работы и взаимодействия с информацией (получение, накопление, переработка, создание на этой основе качественно новой информации, ее трансляция, практическое использование и др.) и знаниями (Л. А. Пронина); б) как составная часть, компонент общей (базисной) культуры личности, характеризующаяся информационным аспектом проявления в виде информационного мировоззрения, информационной грамотности и умелости, информационных способоностей и т. д., позволяющих самостоятельно участвовать во всех видах работы с информацией и взаимодействовать с нею (О. В. Артюшкин, О. О. Борисова, Н. И. Гендина, В. Б. Дудка, И. А. Задонская, С. Д. Каракозов, А. Ю. Квитко, Н. И. Колкова, М. В. Корнилова, Т. Н. Ладожина, Н. Н. Мухина, А. М. Низамеева, Н. А. Паршиков, Г. А. Стародубова и др.); в) как сложное системное качество личности, свойство личности, отражающие в себе в информационном аспекте как общую, так и профессиональную культуру человека - его мировоззрение, деятельность, поведение, общениее и т.д. (Н. Д. Берман, Е. В. Гнатышина, О. Г .Кочеткова, Е. Н. Остроумова) $[1,2,4,6,7,8,10,11,12,14,16,18]$.

То есть видно, что чаще всего информационная культура рассматривается в качестве сложного целостно проявляемого и личностно центрированного феномена, взаимосвязанного со всеми культурами, образующими каркас личности - интеллектуальной, нравственной, правовой, эстетической, творческой и др. А значит и формироваться она должна в качестве составной части каждой из этих культур, интегрируясь в них. При этом заметим, что ряд ученых, учитывая, что информационная культура сегодня глобально характеризует культуру общечеловеческую, детерминирует всю жизнь, фактически выводят её за рамки собственно личности, придают ей субличностные характеристики. Соответственно, определяют её и как основу общечеловеческой культуры, поскольку она регулирует любые информационные взаимодействия (Т. С. Коваль), и как самостоятельную качественную характеристику жизнедеятельности человека в области получения, передачи, хранения и использования информации (М. А. Изимариева, Н. А. Кузнецова, Н. А. Шулик, И. Г. Хангельдиева и др.), и как способ жизнедеятельности в информационном пространстве (А. Ю. Квитко).

Но каков же тогда функционал информационной культуры личности, если она так значима? Исследователи единодушны, что в современном мире она реализует важнейшие, по сути, системообразующие функции, обеспечивающие гармоничное цивилизационное развитие личности и общества. Анализ научных подходов (М. Ф. Алиева, Н. Ф. Аникина, Р. В. Беляев, Е. Т. Булгакова, Е. В. Гнатышина, С. В. Гордина, Е. И. Григорьева, А. Н. Дулатова, И. А. Задонская, Н. Б. Зиновьева, Ю. С. Зубов, И. А. Иванова, С. Д. Каракозов, А. Ю. Квитко, Т. С. Коваль, Г. М. Коджаспирова, 
А. Ю. Коджаспиров, В. Н. Михайловский, Л. А. Пронина, Н. А. Сляднева, И. Г. Хангельдиева и др.) позволил выделить следующие функции информационной культуры как комплексного социального и психолого-педагогического феномена:

- сочиально-регулятивная и сочиализирующая функция: выступает методическим аппаратом оперирования всеми видами социальной информации, сложившейся в ходе эволюции общества; обеспечивает понимание природы информационных процессов и отношений, формируя информационную ценностно-смысловую сферу, объединяющую людей; обеспечивает повышение уровня, качества и отдачи контактов (способов, форм, средств) людей со средой обитания; обеспечивает возможность объединять сообщество в единую систему на основе информационного сопряжения и интеграции национальных, этнических, возрастных, социальных, профессиональных и др. субкультурных знаний, умений, норм и ценностей в совместный опыт человечества; позволяет формироваться группам людей, которые духовно объединены общностью понимания тех проблем, в решение которых они включены; позволяет человеку и отдельным группам отладить своё мировоззрение (информационное мировоззрение) по лекалам мировоззрения информационного общества; является механизмом регулирования взаимодействия внутреннего мира человека с миром внешним, обеспечивая его развитие и достижение сбалансированной гармонии; представляет личности возможность легкого выхода в информационное существование, осуществлять информационную жизнь на всех уровнях от глобального до локального; предоставляет различные модели и форматы образцов и способов жизнедеятельности человека в информационном обществе с опорой на систему определенных ценностей и представлений; задает свод правил поведения человека в информационном обществе, способы и нормы общения, в том числе с системами искусственного интеллекта, что позволяет человеку свободно ориентироваться в информационном пространстве, продуктивно и бесконфликтно участвовать в его формировании и изменении;

- коммуникативная функция: выступает информационно-парадигмальным каркасом выражения и поддержания коллективной и индивидуальной культуры бытового и делового общения, задает параметры содержания, предлагает вариативные средства и технологии общения и взаимодействия людей; предлагает совокупность принципов, технологий, реальных механизмов и средств, обеспечивающих принципиально новые формы связей (общения и взаимодействия) отдельных людей и целых коллективов без личного контактного присутствия в режиме удаленного диалога, формируя принципиально новый образ коммуникативной жизни;

- образовательная функиия: позволяет удовлетворять информационные потребности людей в учебной, научно-познавательной и исследовательской деятельности; выступает индикатором достижения необходимой интеллектуальной составляющей общей культуры личности; предоставляет контент самообразовании и образовании личности;

- защитная функция: является стратегическим ориентиром и инструментом обеспечения информационной безопасности и защищенности личности в современном информационном обществе;

- функиия обеспечения культурно-исторической преемственности и развития культуpbl: обеспечивает сохранение и приумножение ранее созданного контента культуры, распространение и потребление объектов культуры [1-3, 5, 8-17];

Чтобы все эти функции реализовывались в полном объеме и как надо, человеку необходимо уметь и быть способным их реализовывать, т. е. на деле персонально демонстрировать соответствующую информационную культуру. Это, собственно, ответ на вопрос, что конкретно надо 
формировать, когда мы говорим о формировании у личности информационной культуры. Обобщая имеющиеся в науке взгляды и подходы $[1,2,4-7,9,12-14,16,18$ и др.], отметим, что своё субъектное проявление на уровне личности информационная культура находит:

- в субординирующих друг друга информационном мировоззрении, информационном поведении, информационном мышлении и информационной деятельности, а именно в том, что она выступает как комплекс специфических способностей, знаний, умений и навыков. Это прежде всего совокупность информационных представлений, знаний, умений, навыков, специфических способностей, владения стилями, способами и средствами информационной деятельности и мышления, обеспечивающих комфортность человека, продуктивность и безопасность его коммуникаций и всего спектра реакций на контакт с информационной средой, свободное, оптимальное удовлетворение индивидуальных информационных потребностей и предпочтений (социальных, профессиональных, досуговых) с использованием как традиционных, так и новых информационных средств и технологий. Они локализуются и проявляются у каждого отдельной личности:

- в области осознания себя принадлежащей информационному миру и самореализующейся в нём: способность воспринимать информацию в качестве калибровочного инструмента понимания сущности и роли информационных явлений и процессов в обществе; способность к обретению, поддержанию и развитию личностного смысла информационной деятельности и поведения, и проецируемая на этой основе способность осуществлять свободный и ответственный выбор этого поведения и деятельности; способность и умение ориентироваться в быстро меняющихся потоках социальной информации, не теряться в них, критически их оценивать, выстраивать свою собственную систему информационной иерархии и доминант; потребность в достижении социально необходимого и персонально значимого уровня информированности, стремление развивать свой тезаурус, свою информационную компетентность; способность и умение адаптироваться к условиям информационного возмущения, рационально защищаться от информационного шума;

- в области владения информационными средствами: умение грамотно и эффективно пользоваться средствами телематики, глобальными и локальными информационно-вычислительными сетями, другими современными средствами поиска, извлечения, обработки, анализа, систематизации и хранения знаний;

- в области работы и взаимодействия с информацией: способность и умение работать с различными источниками информации, осознавая их сильные и слабые стороны; умение применять информационный подход в анализе различных по своей сути объектов и явлений в обществе и природе; способность и умение действовать в условиях как недостаточной, так и избыточной информации, эффективно перерабатывать (анализировать, переосмысливать, синтезировать, разновекторно свертывать и развертывать) эту информацию, оценивать ее качественную сторону, выделять в информации главное и второстепенное, выбирать из массива разноформатной и разноплановой информации наиболее достоверную, важную и нужную; умение устанавливать ассоциативные связи между схожими и различными информационными сообщениями; способность интерпретировать информацию для продуктивного использования в личных целях и донесения её смысла и значения другим её потребителям; умение переводить визуальную информацию в вербальную знаковую систему и наоборот; владение стилями и приемами интеллектуальной деятельности, регулирующими, в частности, осуществление поисковой, изобретательской, научно-исследовательской деятельности; умение 
осуществлять «информационный штурм» с целью осмысления теоретических и практических задач, просчитывать и разрабатывать пути их решения и ставить новые задачи, используя методологические ориентиры и знания информатики;

- в области осуществления коммуникаций: способность и умение воспринимать и передавать информацию, понимать и выражать мысли и чувства в устной, письменной, графической и любой другой форме в рамках бытового и делового общения и взаимодействия, в том числе с использованием возможностей компьютерной (гаджетовой) коммуникации; знание закономерностей и особенностей эмоционального воздействия различного рода информации и способов её преподнесения на других людей и на себя самого, умение учитывать и использовать это при построении коммуникации и др.

Анализ общего массива проявлений информационной культуры в её функциональном и субъектном планах позволяет сделать вывод, что она имеет многоярусную структуру, определяемую несколькими базовыми параметрами.

- Мировоззренческий параметр информационной культуры опирается на ценностно-смысловую сферу личности, ее мотивы, потребности, цели, стремления в сфере функционирования информации; включает осознание феноменологической сущности информации и информационных ресурсов, осмысление места и роли информационной культуры в контексте общей культуры личности и общества в целом, принятие их ценности для гармоничной жизнедеятельности каждой личности; предполагает познание законов и механизмов порождения и распространения информации в обществе.

- Психологический параметр подразумевает наличие развитой информационной рефлексии личности, способность её к адекватной оптимальной ответной реакции на поступление информации, выработку конструктивных мотивов и способов соответствующего поведения; позволяет разобраться в действительности и адекватности данных, которые содержатся в большом потоке поступающей информации; эффективность в плане сохранения душевного и физического здоровья, а также обеспечения конструктивности деятельности и общения, способность переносить информационный шок, справляться с избыточной информацией, свертывать и развертывать имеющиеся информационные блоки; выработанная привычка оперативно перерабатывать поступающую информацию, не зацикливаясь на пиковых формах её проявления.

- Морально-этический параметр информационной культуры представлен личной ответственностью за получение, использование, хранение, распространение информации в обществе; он служит барьером дезинформации, плагиата, препятствует обращению социально-деструктивной информации, определяет границы локус-контроля за совершение действий с информацией.

- Социальный параметр отвечает за уровень информированности личности, без которого невозможен процесс её социализации, а соответственно, невозможно и выполнение личностью многообразных функций в обществе.

- Технологический параметр отвечает за поиск, хранение и переработку информации, для чего необходимо овладеть информационной грамотностью и компетентностью во всех аспектах их проявления, в частности: информационно-коммуникационными технологиями, компьютерной грамотностью, культурой чтения, способами формализации информации, способами разноканального информационного взаимодействия, аналитико-синтетической обработки информации и др.

Выше уже было отмечено, что каждым своим параметром информационная культура присутствует во всех видах культуры личности. А потому она может быть представлена определенным рядом компонентов в целостной структуре личности. Мы в качестве основных выделяем ког- 
нитивный, ценностно-смысловой и содержательный (деятельностно-практический) компоненты, реализующиеся на практике в тесной взаимосвязи, порождая синергетический функциональный эффект. Эти компоненты являются теми укрупненными функционально-содержательными блоками информационной культуры, которые помогают систематизировать работу по её формированию и диагностике одновременно и совместно с формированием интеллектуальной, нравственной, правовой, эстетической, творческой и др. культурами личности.

- Когнитивный компонент предусматривает в первую очередь информационную грамотность, означающую владение знаниями об информационной среде, о законах функционирования информации в обществе, об общих закономерностях протекания информационных процессов в разного рода живых (природных и социальных) и технических системах, о компьютере как системе, о правовых нормах, регулирующих информационные отношения и функционирование информации, что должно порождать чувство ориентационной уверенности, будучи включенным в мир информации. Именно когнитивному компоненту целесообразно отвести ответственность за проявление познавательной, поисково-прикладной активности, алгоритмическое мышление, за совершенствование знаний в области информатики как системы, проявление нестандартного мышления в решении стандартных задач. Он также проявляется в кругозоре, эрудиции, осведомленности о разнообразных информационных процессах как с позиций научного знания, так и с точки зрения житейского опыта, извлекаемого из непосредственного общения человека с окружением, почерпнутого из средств массовой информации. Это дает понимание основ функционирования информационного общества, роли развития информационных технологий и т. д. Всё это в совокупности часто определяется как информационная картина мира, имеющая у каждого человека своё собственное наполнение и проявления.

В когнитивном компоненте информационной культуры целесообразно выделить и компьютерную грамотность, предполагающую совокупность знаний, умений и навыков использования компьютера и другой информационной техники. Она является регулятором информационной деятельности и на сегодня, и на перспективу, обеспечивает инструментальную умелость в поиске и обработке информации, в установлении и поддержании контактов в современной обстановке глобальной информатизации общества.

- Ценностно-смысловой компонент информационной культуры личности включает в себя мотивационно-ценностные установки, оценки, отношения, характеризующие мотивацию информационной деятельности, доминанту собственных информационных интересов, выбор каналов использования и передачи информации, самооценку удовлетворения своих информационных потребностей, рефлексию и прогнозирование собственной информационной деятельности. К данному компоненту относятся и знания об этических, моральных, правовых нормах деятельности в информационной среде, об информационной безопасности общества и личности, о диагностике информационного поля общества и др., что должно порождать персональное чувство ответственности за приобретенные знания, умения и навыки информационной деятельности (каждый хорошо обученный программист может написать зловредный компьютерный вирус, но не каждый будет это делать), за использование информации в профессиональных, личных и образовательных целях, а также соответствующее чувство безопасности.

Мотивация информационной деятельности во многом определяется местом той или иной информации в системе жизненных ценностей личности. Мотивация и характер удовлетворения информационных потребностей определяют выбор информационных ресурсов и каналов получения необходимой информации, позволяют критически воспринимать и оценивать различные негативные проявления в контенте информационной среды, такие, как безвкусица, пошлость, насилие, безнравственность, плагиат и др. 
Взаимосвязь содержания когнитивного и ценностно-смыслового компонентов определяют сформированность у личности информационного мировоззрения, позволяющего понять позитивные и негативные последствия углубления процесса информатизации нашей жизни, осознать пределы границ применимости информационных технологий для соблюдения приоритета ценности человеческой жизни и здоровья в условиях включенности человека в человеко-машинные системы.

- Содержстельный (деятельностно-практический) компонент означает реальное и потенциальное использование способностей, знаний и умений, определяет способы поиска и получения необходимой информации, способы её хранения и передачи, использование различных источников получения информации, «разумное»её применение в собственных и чужих целях. Думается, именно в этом компоненте в полной мере на практике проявляется так называемая информационная компетентность, в которую включается, в частности, способность личности обеспечивать себе свободный доступ к информации, не являющейся тайной; публиковать и разглашать собственную информацию; реализовывать право на свободный выбор провайдера, источника, формата, стандарта информации, программы и технологии работы с информацией; реализовывать доступные и не запрещенные в обществе возможности относительно производства, передачи, распространения, использования, копирования, уничтожения всевозможной информации, включая и собственную информацию и т. д. [5, с. 26].

Деятельностно-практический компонент информационной культуры личности проявляется в методологии построения и осуществления информационной деятельности, в мобильности и гибкости, в умении быстро адаптироваться в информационно-образовательной, информационно-досуговой и др. среде, в саморегуляции поведения в условиях информационных взаимодействий и взаимоотношений, в рефлексии сочетания целей информационной деятельности с постановкой досуговых, учебных и общекультурных задач.

Наряду с вышеизложенным видением компонентов отметим и достаточно интересный структурно-функциональный взгляд Л. А. Прониной на информационную культуру, которую она предложила рассматривать как двухкомпонентную структуру, состоящую из ядра и защитного пояса. Ядро - это система информационных ценностей, информационных норм, информационных знаний, информационных значений и символов. Оно призвано реализовать социально-регулятивную, коммуникативно-репродуктивную и ценностно-ориентационную функции. А умения и навыки информационной деятельности вместе с развитым восприятием информации выступают в качестве защитного пояса, выполняя функции самосохранения, интеграции, достижения цели, адаптации. В целом же информационная культура, как система, по мнению Л. А. Прониной, выполняет защитную, креативную, коммуникативную, сигнификативную, нормативную функции и является стандартом информационного поведения и образа жизни [16].

Заключение / conclusion. Таким образом, можно сделать вывод, что информационная культура личности сегодня реально превратилась в действенный социальный регулятив, выступает одним из основных операциональных понятий всей социальной практики [1, с. 67]. Она включает в себя массу суббъектно-личностных параметров, проявляемых в мировоззрении, мотивации, деятельности и общении, чувствах и эмоциях, практически во всех познавательных процессах. То есть, ставя вопрос о работе по формированию информационной культуры у подрастающего поколения, необходимо и педагогам, и учащимся четко и ответственно понимать, что данная культура - это уже нечто большее, чем просто инструментально-пользовательская характеристика ученика с точки зрения владения им компьютером и информационными технологиями. И оценивать лишь по этим параметрам её сформированность уже нельзя. Это, по сути, системообразующая субкультура, синтезирующая в культуре социальной жизнедеятельности каждого человека его широкий спектр культур: отношения к информации, понимания себя как объекта и субъекта информации, нахождения в информационном поле, поиска информации, отбора информации, использования информации, хра- 
нения информации, работы со средствами информации, переработки информации, преобразования информации, передачи и распространения информации и т. д. в структуре нравственной, правовой, творческой, интеллектуальной, научно-исследовательской, экологической и др. деятельностей. И говоря, в частности, о нравственном или правовом воспитании, мы тем самым должны говорить и о соответствующем информационном воспитании. И наоборот. То есть вопрос формирования информационной культуры у подрастающего поколения требует специального внимания и реагирования каждого, кто занимается воспитанием и обучением. Необходима комплексная согласованная и взаимоподдерживающая работа всех основных институтов образования с учетом целей и потребностей общества и личности «на сегодня» и «на перспективу».

\section{ЛИТЕРАТУРА И ИНТЕРНЕТ-РЕСУРСЫ}

1. Алиева М. Ф. Понятие информационной культуры: факторная и структурная операционализация // Вестник Адыгейского государственного университета. Серия 1: Регионоведение: философия, история, социология, юриспруденция, политология, культурология. 2013. № 1 (113). С. 64-71.

2. Аникина Н. В., Иванова И. А., Гордина С. В. Информационная культура личности как интегральный показатель уровня развития индивида в системе непрерывного образования // Интеграция образования. 2012. № 4. С. 108-113.

3. Беляев Р. В., Григорьева Е. И. Информационная культура личности: ведущие методологические подходы // Вестник МГУКИ. 2016. № 2 (70). С. 90-96.

4. Берман Н. Д. Информационная культура как основа профессиональной деятельности // Современные исследования социальных проблем. 2017. Том: 8. № 6-2. С. 354-358.

5. Булгакова Е. Т. Информационная культура как составляющая профессиональной культуры будущего специалиста-гуманитария // Известия ВГПУ. 2006. № 4. С. 22-28.

6. Гендина Н. И. Информационная грамотность и информационная культура личности: международный и российский подходы к решению проблемы // Открытое образование: научно-практический журнал. 2007. № 5 (64). С. 58-69.

7. Гендина Н. И. Формирование информационной культуры личности: от теории - к модели информационного образования // Открытое образование. 2007. № 1. С. 4-10.

8. Гнатышина Е. В. Информационная культура педагога профессионального обучения: мировоззренческий аспект // Вектор науки Тольяттинского государственного университета. Серия: Педагогика, психология. 2012. № 4 (11). С. 69-71.

9. Дулатова А. Н., Зиновьева Н. Б. Информационная культура личности: учебно-методическое пособие. М.: Либерия-Бибинформ, 2007. 176 с.

10. Задонская И. А. Информационная культура личности как основа формирования информационного общества // Социально-экономические явления и процессы. 2015. Т. 10. № 2. С. 98-104.

11. Каракозов С. Д. Информационная культура в контексте общей теории культуры личности // Пед. информатика. 2000. № 2. С. 41-55.

12. Квитко А. Ю. Информационная культура личности // Научные ведомости БелГУ. Серия: Философия. Социология. Право. 2010. № 2 (73). С.162-169.

13. Коваль Т. С. Развитие содержания понятия «информационная культура личности» // Вестник ТГПУ. 2007. № 7. C. 67-72.

14. Коджаспирова Г. М., Коджаспиров А. Ю. Педагогический словарь: учеб. пособие. М.: Академия, 2003. 176 с.

15. Михайловский В. Н. Формирование научной картины мира и информатизация: Философские очерки. СПб., 1994. 143 с.

16. Пронина Л. А. Информационная культура как фактор развития информационного общества // Аналитика культурологии. 2008. № 10. URL: https://cyberleninka.ru/article/n/informatsionnaya-kultura-kakfaktor-razvitiya-informatsionnogo-obschestva (дата обращения: 06.08.2018).

17. Хангельдиева И. Г. О понятии «информационная культура» // Информационная культура личности: прошлое, настоящее, будущее: тезисы докладов Международной научной конференции, Краснодар Новороссийск, 23-25 сент. 1993 г. Краснодар: КГАК, 1993. С. 2-8.

18. Ходякова Н. В. Личностный подход к формированию информационной культуры выпускников вузов: дис. ... канд. пед. наук: 13.00 .01 . Волгоград, 1996. 170 с. 


\section{REFERENCES AND INTERNET RESOURCES}

1. Alieva M. F. Ponyatie informatsionnoi kul'tury: faktornaya i strukturnaya operatsionalizatsiya (The concept of information culture: factor and structural operationalization) // Vestnik Adygeiskogo gosudarstvennogo universiteta, Seriya 1: Regionovedenie: filosofiya, istoriya, sotsiologiya, yurisprudentsiya, politologiya, kul'turologiya. 2013. No. 1 (113). Pp. 64-71.

2. Anikina N. V., Ivanova I. A., Gordina S. V. Informatsionnaya kul'tura lichnosti kak integral'nyi pokazatel' urovnya razvitiya individa $\mathrm{v}$ sisteme nepreryvnogo obrazovaniya (Information culture of the individual as an integral indicator of the level of development of the individual in the system of continuous education) // Integratsiya obrazovaniya. 2012. No. 4. Pp. 108-113.

3. Belyaev R. V., Grigor'eva E. I. Informatsionnaya kul'tura lichnosti: vedushchie metodologicheskie podkhody (Information culture of personality: leading methodological approaches) // Vestnik MGUKI. 2016. No. 2 (70). Pp. 90-96.

4. Berman N. D. Informatsionnaya kul'tura kak osnova professional'noi deyatel'nosti (nformation culture as the basis of professional activity) // Sovremennye issledovaniya sotsial'nykh problem. 2017. Tom 8. No. 6-2. Pp. 354-358.

5. Bulgakova E. T. Informatsionnaya kul'tura kak sostavlyayushchaya professional'noi kul'tury budushchego spetsialista-gumanitariya (Information culture as a component of professional culture of the future specialist-humanitarians) // Izvestiya VGPU. 2006. No. 4. Pp. 22-28.

6. Gendina N. I. Informatsionnaya gramotnost' i informatsionnaya kul'tura lichnosti: mezhdunarodnyi i rossiiskii podkhody $\mathrm{k}$ resheniyu problem (Information literacy and information culture of the individual: international and Russian approaches to solving the problem) // Otkry toe obrazovanie: nauchno-prakticheskii zhurnal. 2007. No. 5 (64). Pp. 58-69.

7. Gendina N. I. Formirovanie informatsionnoi kul'tury lichnosti: ot teorii $-\mathrm{k}$ modeli informatsionnogo obrazovaniya (Formation of personal information culture: from theory to model of information education) // Otkrytoe obrazovanie. 2007. No. 1. Pp. 4-10.

8. Gnatyshina E. V. Informatsionnaya kul'tura pedagoga professional'nogo obucheniya: mirovozzrencheskii aspect (Information culture of the teacher of vocational training: worldview aspect) // Vektor nauki Tol'yattinskogo gosudarstvennogo universiteta, Seriya: Pedagogika, psikhologiya. 2012. No. 4 (11). Pp. 69-71.

9. Dulatova A. N., Zinov'eva N. B. Informatsionnaya kul'tura lichnosti: uchebno-metodicheskoe posobie (Personal information culture). M.: Liberiya-Bibinform, 2007. 176 p.

10. Zadonskaya I. A. Informatsionnaya kul'tura lichnosti kak osnova formirovaniya informatsionnogo obshchestva (Information culture of the person as a basis for the formation of the information society) // Sotsial'no-ekonomicheskie yavleniya i protsessy. 2015. T. 10. No. 2. Pp. 98-104.

11. Karakozov S. D. Informatsionnaya kul'tura v kontekste obshchei teorii kul'tury lichnosti (Information culture in the context of the General theory of personal culture) // Ped. Informatika. 2000. No. 2. Pp. 41-55.

12. Kvitko A. Yu. Informatsionnaya kul'tura lichnosti (Personal information culture) // Nauchnye vedomosti BelGU, Seriya: Filosofiya. Sotsiologiya. Pravo. 2010. No. 2 (73). Pp. 162-169.

13. Koval' T. S. Razvitie soderzhaniya ponyatiya «informatsionnaya kul'tura lichnosti» (Development of the content of the concept «information culture of the person») // Vestnik TGPU, 2007. No. 7. Pp. 67-72.

14. Kodzhaspirova G. M., Kodzhaspirov A. Yu. Pedagogicheskii slovar' (Pedagogical dictionary): ucheb. Posobie. M.: Akademiya, 2003. 176 p.

15. Mikhailovskii V. N. Formirovanie nauchnoi kartiny mira i informatizatsiya: Filosofskie ocherki (The formation of scientific world picture and information: Philosophical essays). SPb., 1994. $143 \mathrm{p}$.

16. Pronina L. A. Informatsionnaya kul'tura kak faktor razvitiya informatsionnogo obshchestva (Information culture as a factor of information society development) // Analitika kul'turologii. 2008. No. 10. URL: https:// cyberleninka.ru/article/n/informatsionnaya-kultura-kak-faktor-razvitiya-informatsionnogo-obschestva (data obrashcheniya: 06.08.2018).

17. Khangel'dieva I. G. O ponyatii «informatsionnaya kul'tura» (On the concept of "information culture") // Informatsionnay a kul'tura lichnosti: proshloe, nastoyashchee, budushchee: tezisy dokladov Mezhdunarodnoi nauchnoi konferentsii, Krasnodar - Novorossiisk, 23-25 sent. 1993 g. Krasnodar: KGAK, 1993. Pp. 2-8.

18. Khodyakova N. V. Lichnostnyi podkhod k formirovaniyu informatsionnoi kul'tury vypusknikov vuzov (Personal approach to the formation of information culture of University graduates): dis. ... kand. ped. nauk: 13.00.01. Volgograd, 1996. $170 \mathrm{p}$. 


\section{СВЕДЕНИЯ ОБ АВТОРАХ}

Бобрышов Сергей Викторович, доктор педагогических наук, профессор, заведующий кафедры воспитания, социализации и развития личности, ГБОУ ВО «Ставропольский государственный педагогический институт». E-mail: svbobrishov $@$ yandex.ru

Горбатовская Наталья Николаевна, аспирантка кафедры воспитания, социализации и развития личности, ГБОУ ВО «Ставропольский государственный педагогический институт». E-mail: gorbatovsckaya.N@) yandex.ru

\section{INFORMATION ABOUT AUTHORS}

Bobryshov Sergey, Doctor of Pedagogical Sciences, Professor, Head of Department of Education, Socialization and Development of the Individual, State-financed educational institution of higher education «Stavropol State Pedagogical Institute» (SSPI). E-mail: svbobrishov $a$ yandex.ru

Gorbatovsckaya Natalia, doctoral student of the Department of Education, Socialization and Development of the Individual, State-financed educational institution of higher education «Stavropol State Pedagogical Institute» (SSPI). E-mail: gorbatovsckaya.N@yandex.ru 